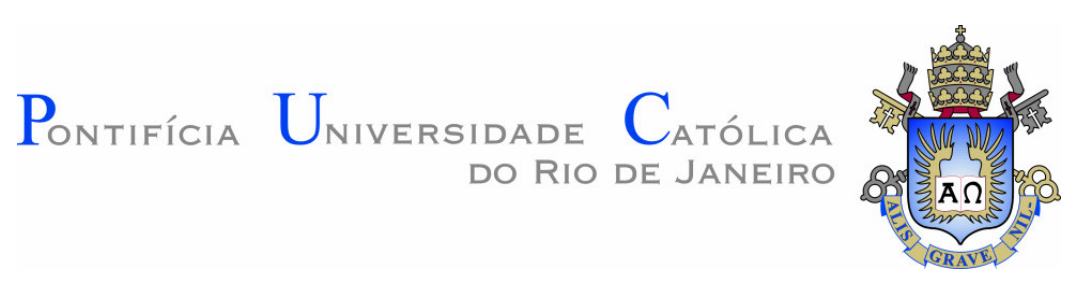

Luciana Fernandes Pacheco

\title{
Microscopia Digital Co-localizada e Espectroscopia de Absorção Atômica na Análise do Efeito Quelante sobre a Dentina Humana
}

\section{Dissertação de Mestrado}

Dissertação apresentada ao programa de pósgraduação em Engenharia Metalúrgica e de Materiais da PUC-Rio como requisito parcial para obtenção do título de Mestre em Engenharia Metalúrgica e de Materiais

Orientador: Prof. Sidnei Paciornik

Rio de Janeiro setembro de 2008 


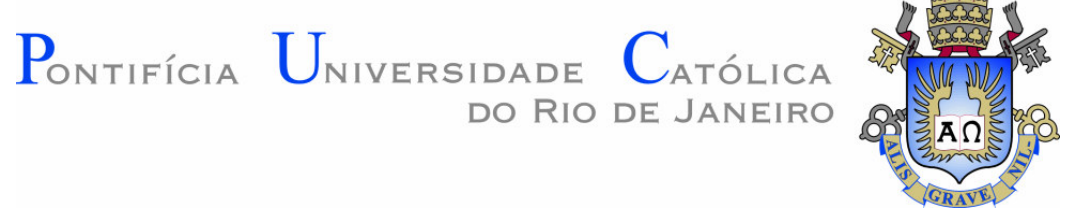

Luciana Fernandes Pacheco

\section{Microscopia Digital Co-localizada e Espectroscopia de Absorção Atômica na Análise do Efeito Quelante sobre a Dentina Humana}

Dissertação apresentada como requisito parcial para obtenção do grau pelo Programa de Pós-graduação em Engenharia Metalúrgica e de Materiais da PUC-Rio. Aprovada pela Comissão Examinadora abaixo assinada.

Sidnei Paciornik

Orientador PUC-Rio

Marcos Henrique de Pinho Mauricio Departamento de Ciências dos Materiais e Metalurgia - PUC-Rio

Luciana Moura Sassone Universidade do Estado do Rio de Janeiro - UERJ

Gustavo André de Deus Carneiro Vianna Universidade Veiga de Almeida - UVA

José Eugenio Leal Coordenador Setorial do Centro Técnico Científico - PUC-Rio

Rio de Janeiro, 5 de setembro de 2008 
Todos os direitos reservados. É proibida a reprodução total ou parcial do trabalho sem autorização da universidade, da autora e do orientador.

\section{Luciana Fernandes Pacheco}

Formação: Graduou-se em Odontologia na UGF em 1997. Especializou-se em Endodontia na UGF em 2001

Ficha Catalográfica

Pacheco, Luciana Fernandes

Microscopia digital co-localizada e espectroscopia de absorção atômica na análise do efeito quelante sobre a dentina humana / Luciana Fernandes Pacheco ; orientador: Sidnei Paciornik. - 2008.

84 f. : il. ; $30 \mathrm{~cm}$

Dissertação (Mestrado em Ciência dos Materiais e Metalurgia)-Pontifícia Universidade Católica do Rio de Janeiro, Rio de Janeiro, 2008.

Inclui bibliografia

1. Ciência dos Materiais e Metalurgia - Teses. 2. Descalcificação da dentina. 3. Microscopia digital colocalizada. 4. Análise de imagens. 5. Quelantes. 6. Espectroscopia de absorção atômica. 7. MTAD. 8. HEBP. 9. EDTA. I. Paciornik, Sidnei. II. Pontifícia Universidade Católica do Rio de Janeiro. Departamento de Ciência dos Materiais e Metalurgia. III. Título.

CDD: 669 
Aos meus pais, José e Ana Maria, que sempre me incentivaram e ajudaram na realização deste sonho.

Para Simone, minha irmã: Obrigada por estar ao meu lado nas horas difíceis, e por compreender meus momentos de impaciência. 


\section{Agradecimentos}

Ao meu orientador, Sidnei Paciornik, pela grande dedicação nesses dois anos de convivência. Sempre esteve disposto a me ajudar, a qualquer hora, qualquer dia, e em qualquer lugar que estivesse. Obrigada por me ajudar a concluir essa importante etapa da minha vida, sempre lutando por mim e facilitando a minha trajetória. Obrigada por compreender que eu tinha outras obrigações durante o curso de mestrado, nunca exigindo total exclusividade. Obrigada por transmitir de forma clara seus conhecimentos nas disciplinas do curso e principalmente na área computacional, sempre com muita paciência.

Ao amigo e professor, Gustavo De Deus. Obrigada por me incentivar ao curso de mestrado no departamento de materiais e metalurgia da PUC. Sem seu empurrão não teria chegado aqui. Sempre com muita paciência me esclareceu as dúvidas clínicas e acadêmicas. Obrigada por ler e reler meus textos inúmeras vezes, fazendo as correções com muita clareza e disposição. Admiro muito seu amor pelo ensino.

A minha grande amiga e professora Karla Baumotte. Foi inspirada em você que dei esse rumo na minha vida. Sou grata por tudo que já fez e continua fazendo por mim. Nunca vou esquecer as portas que você me abriu. Admiro muito a sua garra, sua vontade de passar seus conhecimentos e dedicação com seus alunos. Obrigada 
por ser minha AMIGA e confidente, e acima de tudo estar por perto nas horas que sempre preciso. Devo a você a vontade de fazer o mestrado.

A mais nova amiga, Claudia Reis, por toda dedicação, empenho, e principalmente paciência, que teve comigo durante esses dois anos. Sem você para me ajudar no preparo das amostras e na manipulação do microscópio óptico, não teria chegado até aqui. Saiba que gostaria de retribuir toda sua ajuda.

Aos professores do DCMM, Marcos Henrique, Roberto Avillez, Zé Roberto entre outros, que com muita clareza souberam passar seus conhecimentos e contribuir para a realização desta tese.

À equipe do laboratório de química da PUC, prof. Reinaldo, Rodrigo e Willian, que ajudaram muito nos experimentos da tese e tiveram rapidez e paciência, quando eu apressava os resultados.

À equipe do laboratório de metalografia, Heitor, Marco Aurélio, Ana Cristina e Ana Rosa, que foram muito eficientes e ágeis na preparação das amostras

Aos meus mestres, Paulo Garcia e Marcelo Mangelli, pelos ensinamentos que muito contribuíram para o meu crescimento profissional. Graças a vocês que aprendi a admirar a endodontia.

As minhas amigas endodontistas, Eliane, Ana Claudia e Elisa. Com vocês o curso de especialização foi prazeroso e divertido. Obrigada por estarem ao meu lado até hoje, e por contribuírem para minha formação pessoal e profissional.

As minhas amigas não endodontistas, Roberta, Luciana e Alessandra, por sempre estarem ao meu lado, sabendo compreender minha correria e nervosismo

Aos meus alunos do curso de atualização da Universidade Gama Filho, que são meu maior incentivo para continuar estudando.

Aos funcionários do DCMM que sempre me ajudaram e se mostraram dispostos sempre que precisei. 
A toda minha família e amigos que contribuíram de alguma forma para esse trabalho. 


\section{Resumo}

Pacheco, Luciana Fernandes; Paciornik, Sidnei. Microscopia Digital Colocalizada e Espectroscopia de Absorção Atômica na Análise do Efeito Quelante sobre a Dentina Humana. Rio de Janeiro, 2008. 84p. Dissertação de Mestrado - Departamento de Ciência dos Materiais e Metalurgia, Pontifícia Universidade Católica do Rio de Janeiro.

A partir dos anos 70 constatou-se a formação de uma massa aderida às paredes do canal radicular, após a instrumentação, que foi denominada "smear layer". Esta camada é composta de material orgânico e inorgânico, tecido pulpar e bactérias, e contribui para obliterar os túbulos dentinários. A remoção desta camada melhora a adaptação entre o material obturador e as paredes dentinárias, elimina bactérias, limpa e alarga os túbulos. Essa remoção é realizada por soluções quelantes, mas a substância e o tempo ideais permanecem desconhecidos. Os quelantes atuam removendo Cálcio da microestrutura dentinária. No presente estudo, foi analisado o poder quelante de MTAD, HEBP e EDTA sobre a dentina coronária, avaliando a fração de área tubular aberta (AreaP) e a massa de Cálcio quelado ( $\mathrm{MNC}(\mathrm{Ca})$ ). Três hipóteses foram propostas e testadas: Não existe diferença entre os quelantes quanto a AreaP (H1) e quanto a $\mathrm{MNC}(\mathrm{Ca})(\mathrm{H} 2)$; existe correlação entre AreaP e $\mathrm{MNC}(\mathrm{Ca})$ (H3). Através de Microscopia Óptica Co-localizada (MCL) foram capturadas imagens de vários campos de cada amostra, em diferentes tempos de ataque ácido. Uma seqüência de processamento e análise de imagens foi utilizada para medir AreaP versus tempo, para cada quelante. Esta análise foi complementada qualitativamente com Microscopia Eletrônica de Varredura (MEV). As medidas de $\mathrm{MNC}(\mathrm{Ca})$ foram realizadas por Espectroscopia de Absorção Atômica (AA) sobre as soluções quelantes utilizadas no experimento de MCL. H1 foi negada, com MTAD sendo o mais potente e HEBP o menos potente dos quelantes. Os resultados de MEV corroboram os resultados de MCL. Os resultados de AA apresentaram grande dispersão, mas indicam que $\mathrm{H} 2$ é falsa. $\mathrm{H} 3$ foi rejeitada. 


\section{Palavras-chave}

Descalcificação da Dentina; Microscopia Digital Co-Localizada; Análise de Imagens; Quelantes; Espectroscopia de Absorção Atômica; MTAD; HEBP; EDTA 


\section{Abstract}

Pacheco, Luciana Fernandes; Paciornik, Sidnei. Co-Site Digital Microscopy and Atomic Absorption Spectroscopy in the Analysis of the Chelating Effect on Human Dentine. Rio de Janeiro, 2008. 84p. Masters Dissertation - Departamento de Ciência dos Materiais e Metalurgia, Pontifícia Universidade Católica do Rio de Janeiro.

In the 70's it was discovered that after instrumentation of the root canal there was the formation of a smear layer, attached to the walls of the canal. This layer is composed of organic and inorganic material, pulp tissue and bacteria, and contributes to the obliteration of the dentine tubules. The removal of this layer improves the adaptation of the filling material to the dentine walls, eliminates bacteria, cleans and enlarges the tubules. Smear layer removal is achieved through the use of chelators but the ideal substance and application time remain unknown. Chelators act through the removal of Calcium from the dentine microstructure. In the present study, the chelating power of MTAD, HEBP and EDTA on coronal dentine was analyzed through the measurement of the area fraction of open tubules (AreaP) and of the chelated Calcium mass ( $\mathrm{MNC}(\mathrm{Ca}))$. Three hypotheses were proposed and tested: There is no difference between chelators regarding AreaP ( $\mathrm{H} 1)$ and regarding $\mathrm{MNC}(\mathrm{Ca})(\mathrm{H} 2)$; there is correlation between AreaP and $\mathrm{MNC}(\mathrm{Ca})(\mathrm{H} 3)$. Images of several fields of each sample, for different chelation times, were acquired through Co-Site Optical Microscopy (CSOM). An image processing and analysis sequence was employed to measure AreaP versus time, for each chelator. This analysis was qualitatively complemented by Scanning Electron Microscopy (SEM). Measurements of $\mathrm{MNC}(\mathrm{Ca})$ were obtained by Atomic Absorption Spectroscopy (AA) from the chelator solutions used during the CSOM experiments. H1 was denied, with MTAD found to be the most powerful chelator while HEBP was the weakest. SEM results corroborate these findings. AA results showed wide dispersion but indicate that $\mathrm{H} 2$ is false. $\mathrm{H} 3$ was rejected. 


\section{Keywords}

Dentine Demineralization; Co-site Digital Microscopy; Image Analysis;

Chelators; Atomic Absorption Spectroscopy; MTAD; HEBP; EDTA 


\section{Sumário}

1 INTRODUÇÃO 17

2 OBJETIVOS E HIPÓTESES 20

3 REVISÃO BIBLIOGRÁFICA 21

3.1. Dentina 21

3.2. Permeabilidade Dentinária 22

3.3. Smear Layer 24

3.4. Substâncias Quelantes 25

3.4.1.EDTA 26

3.4.1.1.A química do EDTA 27

3.4.1.2.Modo de ação do EDTA 27

3.4.2.EDTA e suas associações 28

3.4.3.Ácido cítrico $\quad 29$

3.4.4.MTAD 30

$\begin{array}{ll}\text { 3.4.5.HEBP } & 31\end{array}$

4 MATERIAIS E MÉTODOS 33

4.1. Seleção dos dentes 33

4.2. Preparação Metalográfica 33

4.3. Parâmetros Experimentais 34

4.3.1.Remoção do Smear Layer $\quad 35$

4.3.2.Diâmetro dos Furos $\quad 35$

4.3.3.Uso da pipeta 37

4.3.4.Aplicação dos Ácidos e Tempos Experimentais 37

4.3.5.Número de Campos para Microscopia Co-Localizada 38

4.3.6. Obtenção de Imagens de Microscopia Eletrônica de Varredura 38

4.4. Microscopia Óptica Digital Co-Localizada 38

4.5. Processamento e Análise Digital de Imagens (PADI) 40 
4.6. Absorção Atômica de Cálcio 43

4.7. Microscopia Eletrônica de Varredura 43

5 RESULTADOS E DISCUSSÃO 44

5.1. Introdução 44

5.2. Análise por Microscopia 45

5.2.1.Experimentos de Calibração 45

5.2.1.1.Dente CAL1 45

5.2.1.2.Dente CAL2 47

5.2.1.3.Dente CAL3 50

5.2.2. Experimentos Comparativos $\quad 54$

5.2.2.1.Dente COMP1 54

5.2.2.2.Dente COMP2 58

5.2.3.Discussão dos resultados de microscopia 62

5.3. Análise por Absorção Atômica 65

5.3.1.Experimentos de Calibração 65

5.3.1.1.Dente CAL1 65

5.3.1.2.Dente CAL2 66

$\begin{array}{ll}\text { 5.3.1.3.Dente CAL3 } & 67\end{array}$

5.3.2.Experimentos Comparativos 68

5.3.2.1.Dente COMP1 68

5.3.2.2.Dente COMP2 69

5.3.3.Discussão dos resultados de absorção atômica 70

5.4. análise de correlação entre mcl e aa 71

5.5. descalcificação com quelante não saturado 72

6 CONCLUSÕES $\quad 75$

7 REFERÊNCIAS BIBLIOGRÁFICAS 76

8 APÊNDICE - Rotina de processamento de imagens 81 


\section{Lista de figuras}

Figura 1: Estruturas que compõem o dente 21

Figura 2: Canalículos Dentinários $\quad 22$

Figura 3: Ilustração do corte das amostras embutidas em resina epóxi

com exposição da dentina do terço cervical das raízes. 34

Figura 4: Pinça perfuradora com diferentes diâmetros 36

Figura 5: Furos grandes e afastados 36

Figura 6: Furos pequenos e próximos 37

Figura 7: Laboratório de Microscopia Digital (DCMM PUC-Rio) 39

Figura 8: Ilustração do recipiente utilizado para o ataque ácido sem remover a amostra do microscópio. 39

Figura 9: Desenho esquemático ilustrando a região de análise da amostra de dentina e os campos capturados automaticamente pelo sistema.

Figura 10: Dente CAL1 - Evolução microestrutural para EDTA. As linhas, de cima para baixo, correspondem aos tempos 0, 60, 180 e 300s. 45

Figura 11: AreaP X Tempo para os 3 furos do Dente CAL1 46

Figura 12: Dente CAL2 - Evolução microestrutural para EDTA. As linhas, de cima para baixo, correspondem aos tempos $0,15,30,60,180$ e 300s. $\quad 48$

Figura 13: AreaP X Tempo 49

Figura 14: Dente CAL2 (FURO1=EDTA). (a) SE 84x; (b) SE 1500x;

(c) BSE 1500x 50

Figura 15: Dente CAL3 - Evolução microestrutural para EDTA. As linhas, de cima para baixo, correspondem aos tempos $0,15,30,60,180$ e 300s. $\quad 51$

Figura 16: AreaP x tempo 52

Figura 17: Dente CAL3 - EDTA. Microestrutura após 300s de ataque.

MEV, 1500X, SE (esquerda) e BSE (direita). As linhas correspondem aos 3 furos.

Figura 18: Dente COMP1- Evolução microestrutural para 3 ácidos. As linhas, de cima para baixo, correspondem aos tempos 0,15, 30, 60, 180 e 300s. $\quad 55$

Figura 19: AreaP X Tempo 56

Figura 20: Dente COMP1. Microestrutura após 300s de ataque. MEV, 1500X, 
SE (esquerda) e BSE (direita). As linhas, de cima para baixo, correspondem aos ácidos MTAD, HEBP e EDTA.

Figura 21: Dente COMP2 - Evolução microestrutural para 3 ácidos. As linhas, de cima para baixo, correspondem aos tempos $0,15,30,60,180$ e 300s. $\quad 59$

Figura 22: AreaP X Tempo

Figura 23: Dente COMP2. Microestrutura após 300s de ataque. MEV, 1500X, SE (esquerda) e BSE (direita). As linhas, de cima para baixo, correspondem aos ácidos MTAD, HEBP e EDTA. 61

Figura 24: $\mathrm{MNC}(\mathrm{Ca}) \mathrm{X}$ Tempo $\quad 65$

Figura 25: $\mathrm{MNC}(\mathrm{Ca}) \mathrm{X}$ Tempo 66

Figura 26: $\mathrm{MNC}(\mathrm{Ca}) \mathrm{X}$ Tempo $\quad 68$

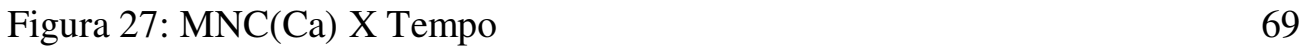

$\begin{array}{ll}\text { Figura 28: } \mathrm{MNC}(\mathrm{Ca}) \mathrm{X} \text { Tempo } & 70\end{array}$

Figura 29: AreaP X MNC(Ca) 71

Figura 30: AreaP X MNC(Ca) 71

Figura 31: Quantidade de Cálcio quelado em função do tempo. 74 


\section{Lista de tabelas}

Tabela 1: Amostras e condições experimentais 34

Tabela 2: Dente CAL1 - Fração de Área ocupada por túbulos abertos 46

Tabela 3: Dente CAL2 - Fração de Área ocupada por túbulos abertos 47

Tabela 4: Dente CAL3 - Fração de Área ocupada por túbulos abertos 52

Tabela 5: Dente COMP1 Fração de Área ocupada por túbulos abertos $\quad 54$

Tabela 6: Dente COMP2 - Fração de Área ocupada por túbulos abertos $\quad 58$

Tabela 7: Comparação Estatística entre os ácidos nos diversos tempos -

Dente COMP1 62

Tabela 8: Comparação Estatística entre os ácidos nos diversos tempos -

Dente COMP2 62

Tabela 9: Dente CAL1 - Resultados de Absorção Atômica 65

Tabela 10: Dente CAL2 - Resultados de Absorção Atômica 66

Tabela 11: Dente CAL3 - Resultados de Absorção Atômica 67

Tabela 12: Dente COMP1 - Resultados de Absorção Atômica 68

Tabela 13: Dente COMP2 - Resultados de Absorção Atômica 69 